\title{
Coronary heart disease and mortality following a breast cancer diagnosis
}

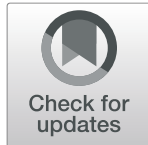

\author{
Aixia Guo ${ }^{1}$, Kathleen W. Zhang ${ }^{2}$, Kristi Reynolds ${ }^{3,4}$ and Randi E. Foraker ${ }^{1,5^{*}}$ (D)
}

\begin{abstract}
Background: Coronary heart disease (CHD) is a leading cause of morbidity and mortality for breast cancer survivors, yet the joint effect of adverse cardiovascular health $(\mathrm{CVH})$ and cardiotoxic cancer treatments on posttreatment CHD and death has not been quantified.

Methods: We conducted statistical and machine learning approaches to evaluate 10-year risk of these outcomes among 1934 women diagnosed with breast cancer during 2006 and 2007. Overall CVH scores were classified as poor, intermediate, or ideal for 5 factors, smoking, body mass index, blood pressure, glucose/hemoglobin A1c, and cholesterol from clinical data within 5 years prior to the breast cancer diagnosis. The receipt of potentially cardiotoxic breast cancer treatments was indicated if the patient received anthracyclines or hormone therapies. We modeled the outcomes of post-cancer diagnosis CHD and death, respectively.
\end{abstract}

Results: Results of these approaches indicated that the joint effect of poor $\mathrm{CVH}$ and receipt of cardiotoxic treatments on CHD (75.9\%) and death (39.5\%) was significantly higher than their independent effects [poor $\mathrm{CVH}$ (55.9\%) and cardiotoxic treatments (43.6\%) for CHD, and poor CVH (29.4\%) and cardiotoxic treatments (35.8\%) for death].

Conclusions: Better $\mathrm{CVH}$ appears to be protective against the development of $\mathrm{CHD}$ even among women who had received potentially cardiotoxic treatments. This study determined the extent to which attainment of ideal $\mathrm{CVH}$ is important not only for CHD and mortality outcomes among women diagnosed with breast cancer.

Keywords: Cancer informatics, Machine learning, Precision medicine, Coronary heart disease, Death, Breast Cancer, Cancer treatments, Interactions

\section{Background}

Coronary heart disease (CHD) is the leading cause of death among all women [1], including breast cancer survivors [2-4]. Increased utilization of screening and treatment has led to more than 3.5 million female breast cancer survivors in the United States today $[5,6]$. The majority of these women are more likely to die of $\mathrm{CHD}$

\footnotetext{
* Correspondence: randi.foraker@wustl.edu

${ }^{1}$ Institute for Informatics (12), Washington University School of Medicine, 600

S. Taylor Avenue, Suite 102, Campus Box 8102, St. Louis, MO 63110, USA

${ }^{5}$ Division of General Medical Sciences, Department of Internal Medicine,

Washington University School of Medicine, 600 S. Taylor Avenue, Suite 102, Campus Box 8102, St. Louis, MO 63110, USA

Full list of author information is available at the end of the article
}

than cancer $[2-4,7,8]$. CHD is a serious issue, because important risk factors, such as physical inactivity, unhealthy diet, obesity, and smoking, are common to the etiology of both CHD and breast cancer [1, 9-11].

Cardiovascular health $(\mathrm{CVH})$, as defined recently by the American Heart Association (AHA), has important implications for the prevention of both CHD and cancer $[12,13]$. CVH factors are believed to operate in common pathways to chronic disease. For example, adverse $\mathrm{CVH}$ factors may be pro-inflammatory and also may be carcinogenic. To date, many community-based studies have used the $\mathrm{CVH}$ metric to characterize the prevalence of ideal $\mathrm{CVH}$ in population-based samples [14-19]. Our previous work in the Women's Health Initiative (WHI)

C The Author(s). 2020 Open Access This article is licensed under a Creative Commons Attribution 4.0 International License, which permits use, sharing, adaptation, distribution and reproduction in any medium or format, as long as you give appropriate credit to the original author(s) and the source, provide a link to the Creative Commons licence, and indicate if changes were made. The images or other third party material in this article are included in the article's Creative Commons licence, unless indicated otherwise in a credit line to the material. If material is not included in the article's Creative Commons licence and your intended use is not permitted by statutory regulation or exceeds the permitted use, you will need to obtain permission directly from the copyright holder. To view a copy of this licence, visit http://creativecommons.org/licenses/by/4.0/. The Creative Commons Public Domain Dedication waiver (http://creativecommons.org/publicdomain/zero/1.0/) applies to the data made available in this article, unless otherwise stated in a credit line to the data. 
found that a poorer ideal $\mathrm{CVH}$ score, comprising the aforementioned factors plus blood pressure, cholesterol, and glucose, was associated with a higher incidence of cardiovascular disease, cancer, and breast cancer specifically [20].

Our evaluation of California cancer registry data highlighted the possible role of shared risk factors in the development of both cancer and CHD, reporting that cancer survivors tend to have multiple CHD risk factors, and that survivorship care often does not address these risk factors [21, 22]. Favorable levels of risk factors common to both CHD and cancer are associated with improved CHD and cancer survival [23]. Yet, in addition to the problem of shared risk factors, therapies used to treat breast cancer are linked with cardiovascular injury, thus increasing CHD susceptibility via the "multiple-hit" hypothesis [24-33]. Breast cancer therapies that are potentially cardiotoxic include chemotherapies, radiotherapy, hormonal treatments, and monoclonal antibodies [24].

To our knowledge, existing studies have not yet assessed the joint effect (interaction) of predisposing cardiovascular risk factors and cancer treatments among breast cancer survivors. Subpopulations, such as breast cancer survivors in poor CVH prior to their cancer diagnosis, may be particularly susceptible to the late effects of chemotherapy, radiation, and other cancer treatments. Thus, this analysis will build on our previous work in the WHI which assessed the relationship between $\mathrm{CVH}$ and incident CHD and cancer [20].

A better understanding of synergistic associations between poor $\mathrm{CVH}$ and breast cancer treatments on $\mathrm{CHD}$ risk after breast cancer has the potential to guide CHD and cancer treatment, as well as post-treatment cancerrelated follow-up care is warranted. Screening and treatment of poor $\mathrm{CVH}$ at the time of cancer diagnosis and treatment planning may improve morbidity and mortality from CHD among breast cancer survivors [4, 21, 3436]. Existing literature indicates that left-sided radiation, in certain doses, has a synergistic effect with pre-existing cardiac risk factors on the risk of ischemic heart disease [17]. Our goal was to add to this literature by investigating the receipt of radiation alongside other types of cancer therapies on risk of CHD and mortality using novel statistical techniques [37].

\section{Methods}

\section{Data source and study design}

In this study, electronic health record (EHR) data was obtained from a large midwestern medical center. The patients $(n=1934)$ were all initially diagnosed with breast cancer during 2006 or 2007 and did not have preexisting CHD. We included follow-up data for 10 years following the initial diagnosis. Our goal was to investigate the association between $\mathrm{CVH}$, potentiallycardiotoxic cancer treatments, age, race, and the 10-year risk of post-treatment $\mathrm{CHD}$ [38] and death, respectively. We defined CHD according to 217 unique ICD 9/10 diagnosis codes and 14 unique procedure codes, and date of death was ascertained from EHR data which were updated regularly with data from the National Death Index.

We utilized measures of $\mathrm{CVH}$ as follows: smoking status, body mass index (BMI), blood pressure, glucose/ hemoglobin A1c, and cholesterol [20], which were introduced by the AHA and shown in detail in Table 1. The most recent $\mathrm{CVH}$ data were ascertained within the 5 years prior to the diagnosis of breast cancer. We used these baseline data to assign a pre-treatment $\mathrm{CVH}$ score to each woman with a breast cancer diagnosis. A value of "ideal" corresponded with 2 points on that submetric; a value of "intermediate" with 1 point; and a value of "poor" with 0 points.

For smoking status, for which data were complete, we classified current smoking as 0 points, and not current smoking as 1 point, as there were no data available to indicate if they had never smoked or had quit for more than 1 year (representing the "ideal" category). However, not all CVH data were completed for all women; therefore, we imputed a value of 2 points for all missing submetric values. We tested the robustness of this strategy by imputing a value of 1 or 0 , respectively, for missing values. For all analyses, overall $\mathrm{CVH}$ was calculated by a sum of all points, divided by the total possible points [10], and multiplied by 100 , and was defined as: $0-<30 \%$ for poor; $30-<80 \%$ for intermediate; and $80-100 \%$ as ideal.

Of interest for these analyses were the following treatments, due to their potential adverse effects on the myocardium: chemotherapy, left-sided radiation, hormonerelated or anti-estrogen pills, and Herceptin. We categorized the breast cancer treatments as eight categories according to what medicines were ordered: anthracyclines, hormone therapy, aromatase inhibitors, monoclonal antibodies, antimicrotubule agents, alkylating agents, antimetabolites, and other (e.g., Bortezomib). In our current analysis, we included the receipt (yes/no) of each type of treatment.

\section{Statistical analysis}

We classified age into three groups: $20-40,41-60$, and $61-100$ years. The age is the age at the breast cancer diagnosis. Race/ethnicity was defined as: black, nonblack, and unknown. After we quantified and categorized the features of $\mathrm{CVH}$, cancer treatments, age, and race, we applied both traditional statistical methods and machine learning algorithms [i.e., support vector machines (SVM) [39], decision tree [40], and logistic regression 
Table 1 Measures of CVH in the EHR (Adapted from Lloyd-Jones, 2011) [38]

\begin{tabular}{|c|c|c|c|}
\hline & Poor Health & Intermediate Health & Ideal Health \\
\hline \multicolumn{4}{|l|}{ Health Behaviors } \\
\hline Smoking status & Yes & Former $\leq 12$ months & $\begin{array}{l}\text { Never or quit > } 12 \\
\text { months }\end{array}$ \\
\hline Body mass index & $\geq 30 \mathrm{~kg} / \mathrm{m}^{2}$ & $25-29.9 \mathrm{~kg} / \mathrm{m}^{2}$ & $<25 \mathrm{~kg} / \mathrm{m}^{2}$ \\
\hline \multicolumn{4}{|l|}{ Health Factors } \\
\hline Total cholesterol & $\geq 240 \mathrm{mg} / \mathrm{dL}$ & $200-239 \mathrm{mg} / \mathrm{dL}$ or treated to goal & $<200 \mathrm{mg} / \mathrm{dL}$ \\
\hline Blood pressure & $\begin{array}{l}\text { Systolic } \geq 140 \mathrm{mmHg} \text { or Diastolic } \geq 90 \\
\mathrm{mmHg}\end{array}$ & $\begin{array}{l}\text { Systolic } 120-139 \mathrm{mmHg} \text { or Diastolic } 80-89 \mathrm{mmHg} \text { or } \\
\text { treated to goal }\end{array}$ & $\begin{array}{l}\text { Systolic }<120 \mathrm{mmHg} \\
\text { Diastolic }<80 \mathrm{mmHg}\end{array}$ \\
\hline $\begin{array}{l}\text { Fasting plasma } \\
\text { glucose }\end{array}$ & $\geq 126 \mathrm{mg} / \mathrm{dL}$ & $100-125$ mg/dL or treated to goal & $<100 \mathrm{mg} / \mathrm{dL}$ \\
\hline
\end{tabular}

[41]] to investigate the associations between age, race, $\mathrm{CVH}$, cancer treatments, the interaction between $\mathrm{CVH}$, cancer treatments, and CHD and all-cause mortality, respectively. We also conducted the Welch's t-test and produced boxplots to evaluate the differences between independent and joint effects of $\mathrm{CVH}$ and cancer treatments. In the machine learning models, we used $\mathrm{CVH}$, treatment and the interaction of $\mathrm{CVH}$ and treatment as features, and applied linear SVM, decision tree, and logistic regression models, respectively, to predict if a woman had incident $\mathrm{CHD}$ or death during 10 years of follow-up. For the death prediction, we randomly selected a similar number of patients who had died $(n=$ 468) to compare to a sample of patients who had not died $(n=374)$ due to the imbalance of our data according to mortality. We used all patient observations in the $\mathrm{CHD}$ risk prediction models. We tested the $5 \mathrm{CVH}$ submetrics and 8 treatment categories as input features for the classification models. The dataset was randomly split into training $(80 \%)$ and test $(20 \%)$ data sets, on which the models were trained and then applied. Criteria of accuracy and area under the receiver operator curve (AUC) were calculated to evaluate the performance of the models. Analyses were conducted by using the libraries of Scikit-learn, Scipy, Matplotlib with Python, version 3.6.5 (2018).

\section{Results}

The average age of the population was 58.5 years, and the majority of women (73\%) were non-black (Table 2). Approximately $20 \%$ of women were currently taking a cholesterol medication, and few women $(3 \%)$ were current smokers (Table 2). There were 341 patients with receipt of any class of cardiotoxic cancer treatments. Among these 341 patients, $46 \%$ women received aromatase inhibitors and $26 \%$ women received hormone therapy. During the 10-year follow-up period, one-third of the population developed CHD and 19\% died.

Figure 1 shows the counts of women with each outcome of interest and the proportion of women represented in that strata. Women with a lower occurrence of CHD were younger (20-40 years), and the prevalence of CHD steadily increased across older age groups (Fig. 1a). Black women experienced a higher occurrence $(48 \%)$ of $\mathrm{CHD}$ compared to the other race groups (31\%) (Fig. 1b). Rates of CHD were lower among women with an ideal $\mathrm{CVH}$ score (24\%) as compared to those with $\mathrm{CVH}$ at non-ideal levels (61.9\%) (Fig. 1c). Receipt of potentially cardiotoxic breast cancer treatments was associated with an increased occurrence of posttreatment CHD. Rates of incident CHD were higher among women who received any cancer treatment (58.9\%) compared to the women who did not receive any cancer treatments (29.1\%) (Fig. 1d). We observed similar trends for the outcome of mortality (Fig. 1e-h). Particularly, Fig. If shows $29 \%$ of the black women died compared to $15.9 \%$ for the non-black race; Fig. 1h shows that higher percentage of patients died in the recipient of treatment group. Women who died during the 10year follow-up tended to be older, of black race, who received cancer treatments, and who had non-ideal $\mathrm{CVH}$.

In Fig. 2, we show the independent and joint effects of receipt of cardiotoxic breast cancer treatments and poorer CVH. Women in poor (non-ideal) $\mathrm{CVH}$ who were also exposed to cardiotoxic treatments had a synergistically higher occurrence of post-treatment CHD (75.9\%) compared to women not exposed to cardiotoxic treatments who were in good CVH (20.8\%) (Fig. 2a). Women in poor CVH who were not exposed to cardiotoxic treatments, as well as women in good $\mathrm{CVH}$ who were exposed to cardiotoxic treatments, had an elevated occurrence of post-treatment CHD (55.9 and 43.6\% respectively), but did not experience a rate as high as those who were doubly-exposed. Similar trends were observed for the outcome of mortality (Fig. 2b). In addition, the independent effect of treatment is bigger on CHD (43.6\%) than on death (35.8\%).

The boxplots in Fig. 2c also indicate the significant difference between CHD rates among women who were doubly-exposed and the women who were independently 
Table 2 Characteristics [mean (SD) or $n(\%)$ ] of the study population $(n=1934)$

\begin{tabular}{|c|c|c|c|}
\hline & Total $(\boldsymbol{n}=1934)$ & $\mathrm{CHD}(\boldsymbol{n}=664)$ & Death $(\boldsymbol{n}=374)$ \\
\hline \multicolumn{4}{|l|}{ Age (years) } \\
\hline Mean (SD) & $58.5(12.9)$ & $62.9(13.1)$ & $61.4(13.9)$ \\
\hline $20-40$ & $135(7.0)$ & $23(3.5)$ & $23(6.1)$ \\
\hline$>40-60$ & $975(50.4)$ & $260(39.2)$ & $159(42.5)$ \\
\hline$>60-100$ & $824(42.6)$ & $381(57.4)$ & $192(51.3)$ \\
\hline \multicolumn{4}{|l|}{ Race } \\
\hline Black & $435(22.5)$ & $209(31.5)$ & $126(33.7)$ \\
\hline Non-black & $1419(73.4)$ & $433(65.2)$ & $226(60.4)$ \\
\hline Unknown & $80(4.1)$ & $22(3.3)$ & $22(5.9)$ \\
\hline BMI $\left(\mathrm{kg} / \mathrm{m}^{2}\right)$ & $21.9(13.6)$ & $29.3(8.3)$ & $28.1(10.1)$ \\
\hline Systolic blood pressure (SBP, mmHg) & $125.4(20.7)$ & $128.4(22.0)$ & $126.0(20.7)$ \\
\hline Diastolic blood pressure (DBP, mmHg) & $69.8(11.2)$ & $69.8(11.6)$ & $69.4(11.4)$ \\
\hline Fasting glucose (mg/dL) & $109.3(33.3)$ & $129.9(53.6)$ & $127.6(58.3)$ \\
\hline Hemoglobin A1c (\%) & $6.94(1.9)$ & $7.05(1.8)$ & $7.45(2.3)$ \\
\hline Total cholesterol (mg/dL) & $186.6(50.3)$ & $181.6(46.6)$ & $178.9(61.0)$ \\
\hline Current smoking & $66(3.4)$ & $51(7.7)$ & $18(4.8)$ \\
\hline Taking antihypercholesterolemia medication & $367(19.0)$ & $267(40.2)$ & $88(23.5)$ \\
\hline Taking antihypertensive medication & $461(23.8)$ & $386(58.1)$ & $215(57.5)$ \\
\hline Taking diabetic medications & $346(17.9)$ & $238(35.8)$ & $138(36.9)$ \\
\hline \multicolumn{4}{|c|}{ Classes of potentially cardiotoxic cancer treatments ${ }^{a}$} \\
\hline Total patients (\%) receiving treatments & $341(17.6)$ & $201(30.3)$ & $128(34.2)$ \\
\hline Anthracyclines & $6(1.8)$ & $4(2.0)$ & $3(2.3)$ \\
\hline Hormone therapy & $87(25.5)$ & $51(25.4)$ & $28(21.9)$ \\
\hline Aromatase inhibitors & $158(46.3)$ & $97(48.3)$ & $44(34.3)$ \\
\hline Monoclonal antibodies & $7(2.1)$ & $3(1.5)$ & $2(1.6)$ \\
\hline Antimicrotubule agents & $15(4.4)$ & $9(4.5)$ & $9(7.0)$ \\
\hline Alkylating agents & $21(6.2)$ & $12(6.0)$ & $12(9.4)$ \\
\hline Antimetabolites & 37 (10.9) & $20(10.0)$ & $27(21.1)$ \\
\hline Other & $10(2.9)$ & $5(2.5)$ & $3(2.3)$ \\
\hline
\end{tabular}

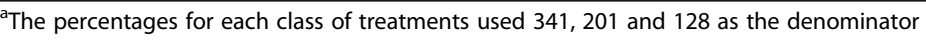

exposed to poor CVH and cancer treatments $(p<0.0001$ for poor CVH vs. joint exposure, $p<0.0001$ for cancer treatments vs. joint exposure). We observed similar results for the outcome of mortality shown in Fig. $2 \mathrm{~d}(p<$ 0.0001 for poor $\mathrm{CVH}$ vs. joint exposure, $p<0.007$ for cancer treatments vs. joint exposure).

We obtained similar results using machine learning models. Table 3/4 (in the supplementary material) lists the performance results for death/CHD prediction by the three models. The accuracy for predicting death by SVM was $69 \%$ for models containing CVH ( $68 \%$ by decision tree, $69 \%$ by logistic regression), $63 \%$ for models containing cancer treatment ( $69 \%$ by decision tree, $66 \%$ by logistic regression) and $70 \%$ for models containing both $\mathrm{CVH}$ and treatment ( $72 \%$ by decision tree, $72 \%$ by logistic regression). The metrics of precision, recall and f1-score had a similar trend for the prediction. The prediction performance results held the same trends for the CHD prediction (Table 4).

The first column in Fig. 3 shows the AUC plots for CHD prediction while the second column shows the prediction characteristics for the outcome of death by SVM, decision tree, and logistic regression classifiers under three different conditions of features: $\mathrm{CVH}$, cancer treatments, and combined $\mathrm{CVH}$ and cancer treatments. The average AUC of the three machine learning models was 0.65 for $\mathrm{CVH}, 0.60$ for cancer treatment, and 0.73 for both $\mathrm{CVH}$ and cancer treatments. We obtained similar results for the mortality analyses. We also performed 10 -fold cross validation for each model and the results were similar (data not shown). 


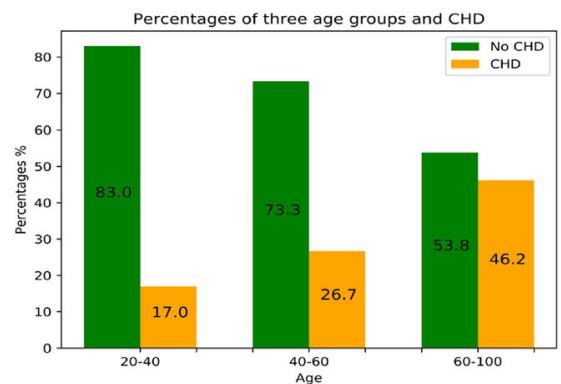

A

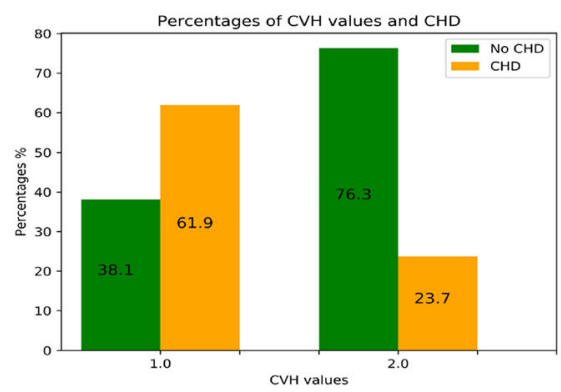

C

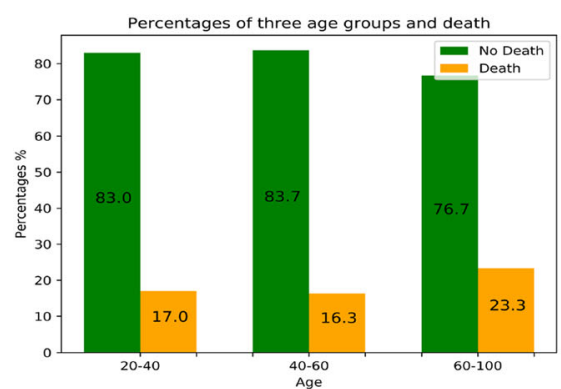

$\mathrm{E}$

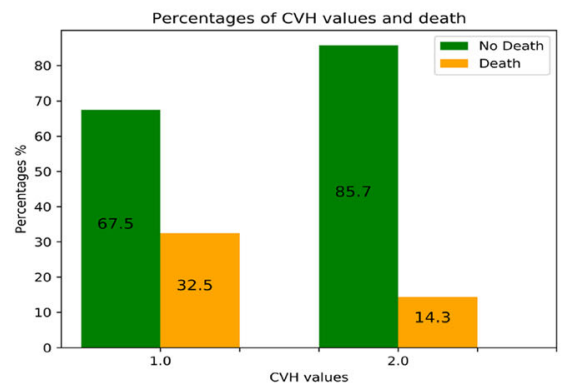

G

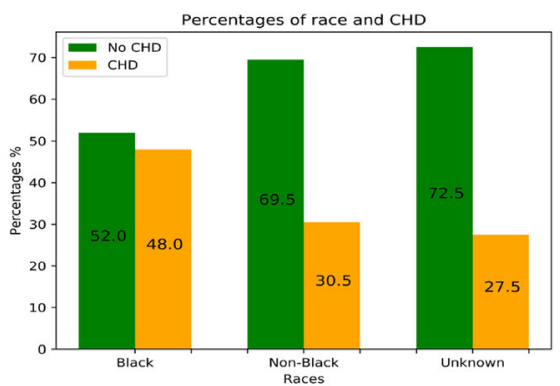

B

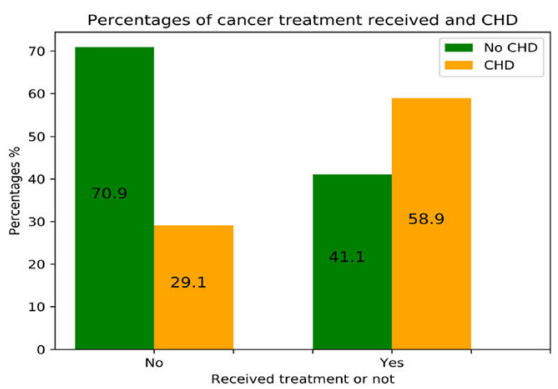

D

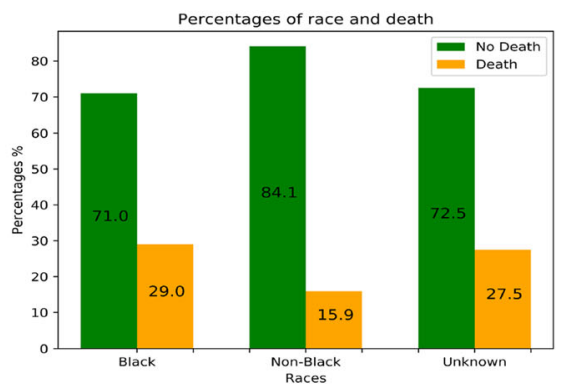

$\mathrm{F}$

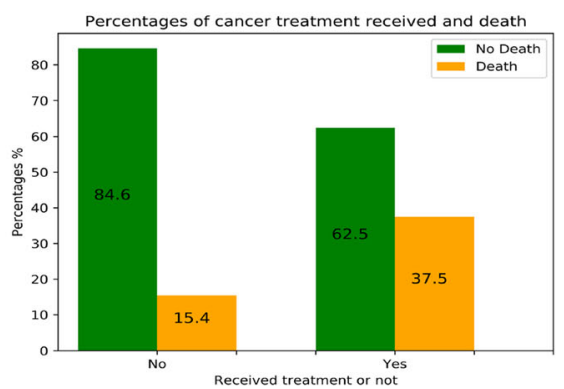

$\mathrm{H}$

Fig. 1 Associations between age, race, CVH, treatment and CHD or death. a-d show associations between age (a), race (b), CVH (c), treatment (d) and CHD. e-h show associations between age (e), race (f), $\mathrm{CVH}(\mathbf{g})$, treatment (h) and death. In $\mathbf{c}$ and $\mathbf{g}$, $\mathrm{CVH}$ is ideal if $\mathrm{CVH}=2.0$, and intermediate if $\mathrm{CVH}=1.0$

The results from Table 3 and Fig. 3 indicate that all three models achieved higher accuracy with the inclusion of joint effects as compared to only individual effects. Specifically, models which include both $\mathrm{CVH}$ and receipt of treatment data provide additional information and improve the prediction of CHD and death. Patients with poor overall $\mathrm{CVH}$ who received cancer treatments had the highest risk of CHD and death.

\section{Discussion}

In this study, we utilized data from the EHR to identify women who were diagnosed with breast cancer in order 


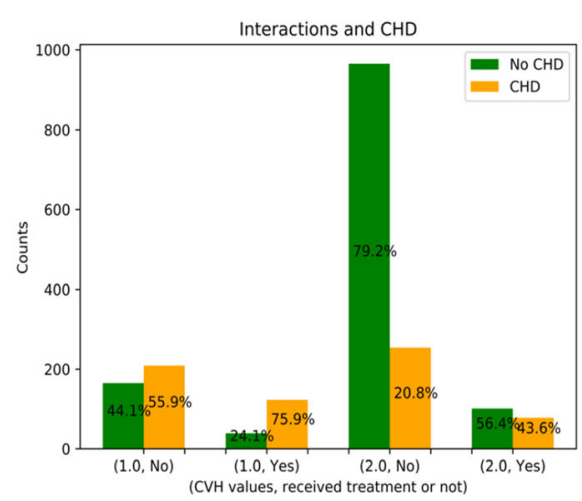

A

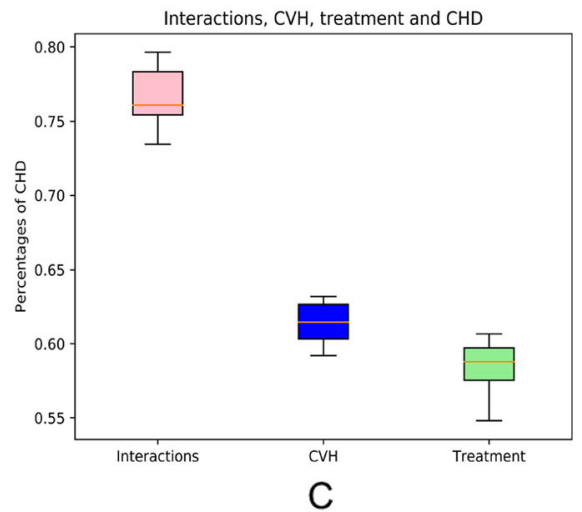

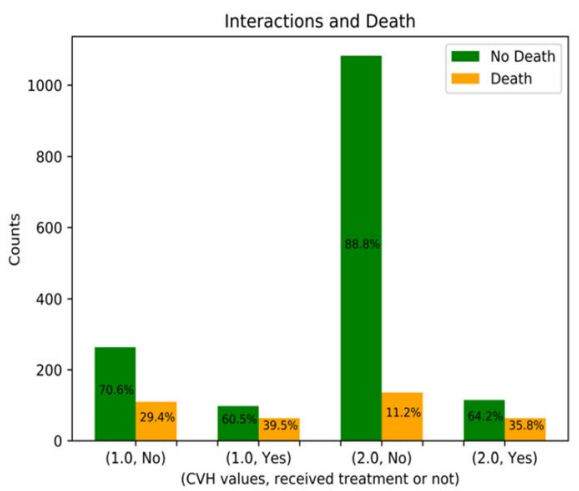

B

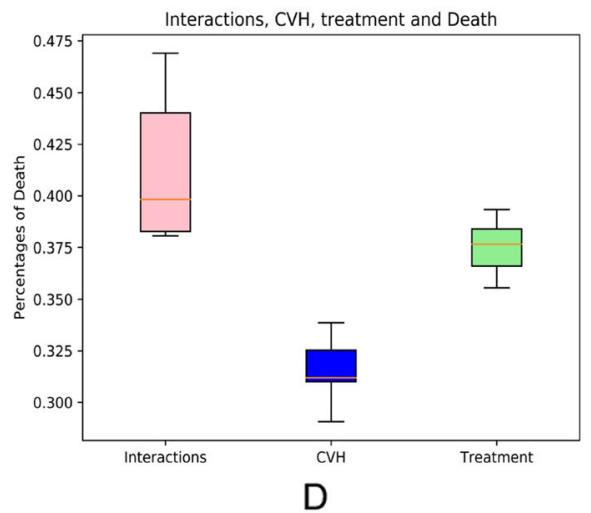

Fig. 2 Associations between joint effects/interactions and CHD or death. a and $\mathbf{b}$ show the contribution of CVH and treatments on CHD (a) and death (b). $\mathbf{c}$ and $\mathbf{d}$ are box plots of the individual and joint (interaction) effects of CVH and treatments on CHD (c) and death (d). In $\mathbf{a}$ and $\mathbf{b}$, CVH is ideal if $\mathrm{CVH}=2.0$, and intermediate if $\mathrm{CVH}=1.0$

to examine the independent and joint effects of $\mathrm{CVH}$ and cancer treatments on 10-year risk of post-treatment CHD or death. Our results indicated women with ideal $\mathrm{CVH}$ scores, and those who did not receive potentially cardiotoxic cancer treatments had the lowest risk of post-treatment CHD or death, while the joint effects of poor $\mathrm{CVH}$ and exposure to cancer treatments significantly increased the risk of post-treatment CHD or death. Additional factors that were associated with a higher prevalence of CHD and death included older age and black race.

Our results were consistent with previous conclusions that minority and older adults were more likely to have poorer $\mathrm{CVH}$ and ideal $\mathrm{CVH}$ was inversely associated with cancers and cardiovascular disease [20]. Consistent with biologic plausibility, our results indicated a higher risk of post-treatment $\mathrm{CHD}$ among those who received breast cancer treatments such as ionizing radiation to the heart [27].

The innovation in this study was to investigate the joint effects of $\mathrm{CVH}$ and potentially cardiotoxic breast cancer treatments by both statistical methods and multiple machine learning approaches. The results from all these methods were consistent, indicating the robustness of our methods and results.

Our next step is to investigate some questions such as which individual treatments (e.g. anthracyclines, hormone therapy) and individual $\mathrm{CVH}$ submetrics (e.g. BMI, blood pressure) are the most important variables for predicting $\mathrm{CHD}$ and death, but these questions are beyond the scope of this paper. We also plan to replicate these analyses in distinct cancer types.

Another next step is to involve deploying and evaluating clinical decision support in the cancer survivorship setting for managing cardiovascular late effects among cancer survivors. Our clinical decision support system (CDSS) presents $\mathrm{CVH}$ and cancer treatment data separately in the EHR-embedded data visualization. Our goal is to 1 day integrate a validated cardiovascular risk algorithm into our existing CDSS to better target cardiovascular disease prevention and management efforts in cancer survivorship.

\section{Limitations}

We encountered many limitations in using EHR data for these analyses. First, there were many missing data for $\mathrm{CVH}$, likely because these women were not being seen 


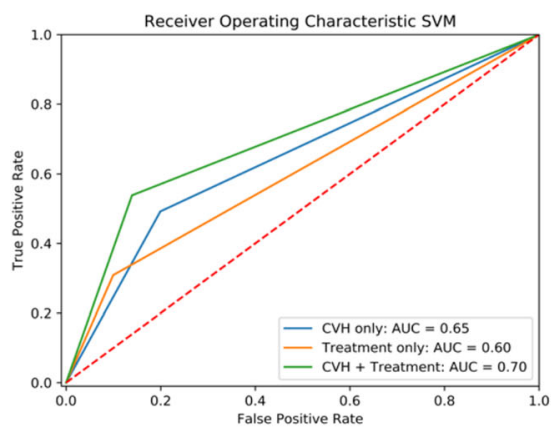

A

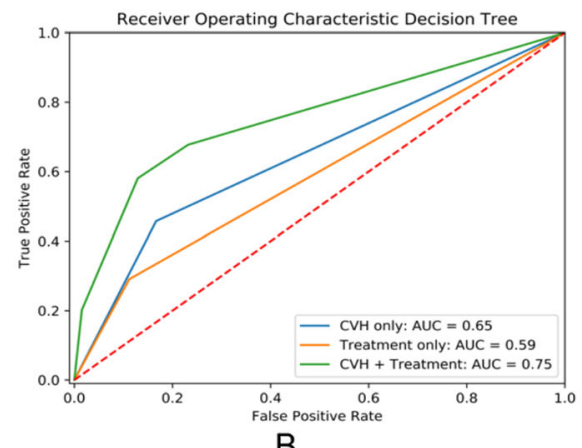

B

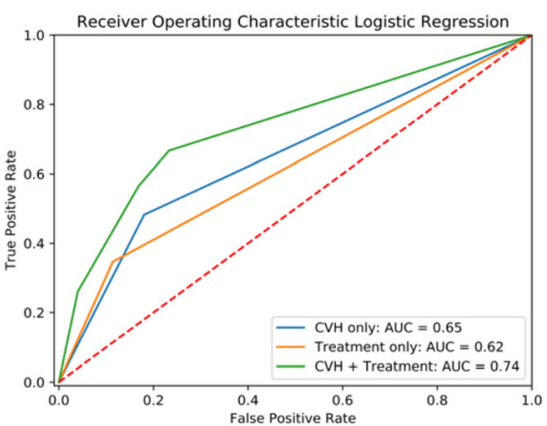

C

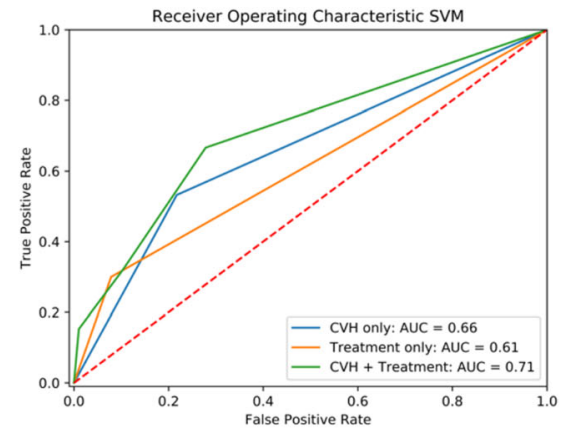

D

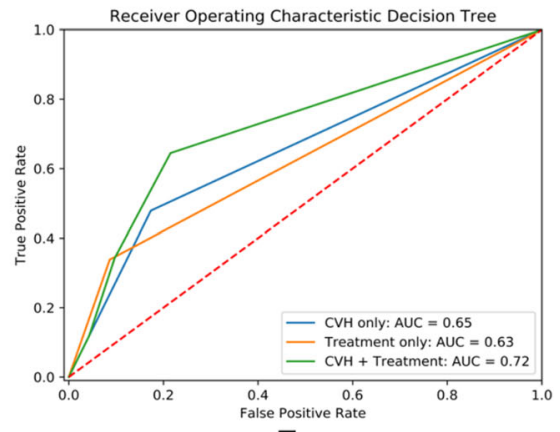

E

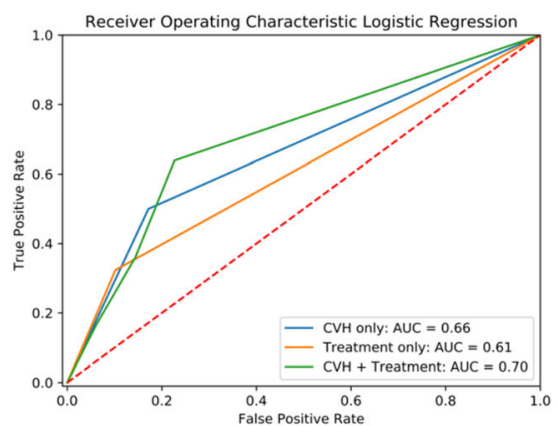

$\mathrm{F}$

Fig. 3 The first column (a-c) represent CHD prediction, and the second column (d-f) show results of mortality prediction. $\mathbf{a}$ and $\mathbf{d}$ show the AUC in ROC by SVM models, $\mathbf{b}$ and $\mathbf{e}$ show the AUC in ROC by decision tree models, and $\mathbf{c}$ and $\mathbf{f}$ show the AUC in ROC by logistic regression models. The three curves in each plot represent the individual and joint effects of $\mathrm{CVH}$ and potentially-cardiotoxic treatments

for preventive care but rather for cancer care and treatment. Second, we acknowledge that we may be missing CHD and mortality outcome data for women who obtained cancer care and treatment at our medical center but after which returned home and sought care outside of our medical center. Third, we used $\mathrm{CVH}$ measurements up to 5 years prior to the cancer diagnosis, of which the time frame varied for each woman. Fourth, physical activity and diet data are not commonly recorded in the EHR as structured, actionable data elements. If physical activity and diet data do exist in the EHR, they are usually recorded as clinical notes using free text. Importantly, these data are not easily translated into the American Heart Association's metric definitions and thus are not actionable at the point-of-care or easily incorporated into risk scoring algorithms. Similarly, data on diagnosis and treatment, have not always been stored as structured data elements in the EHR. Conducting this analysis required mining data from legacy EHR systems and for pragmatic reasons we accessed only structured data elements for this analysis, which resulted in incomplete data ascertainment. Finally, we are missing data on radiotherapy. We will explore the missing radiotherapy data from multiple data sources as our future work.

\section{Conclusions}

An ideal $\mathrm{CVH}$ score predicted a lower risk of posttreatment CHD or death. Receipt of cardiotoxic breast cancer treatments was associated with increased posttreatment CHD or death, and there was a synergistic 
effect of CVH such that better $\mathrm{CVH}$ seemed to be protective against the development of CHD even among women who had received potentially cardiotoxic treatments. This study determined the extent to which ideal $\mathrm{CVH}$ is important to attain and maintain for more favorable outcomes following a breast cancer diagnosis.

\section{Supplementary information}

Supplementary information accompanies this paper at https://doi.org/10. 1186/s12911-020-1127-y.

Additional file $\mathbf{1}$ Table $\mathbf{S 1}$ Performance results of the three models for prediction of the outcome of mortality. Table S2 Performance results of the three models for prediction of the outcome of CHD.

\section{Abbreviations}

CHD: Coronary heart disease; $\mathrm{CVH}$ : Cardiovascular health; AHA: American Heart Association; EHR: Electronic health record; BMl: Body mass index; AUC: Area under the receiver operator curve; SVM: Support vector machines

\section{Acknowledgments}

None.

\section{Authors' contributions}

R.F. contributed to the study design. A.G. conducted the analysis and wrote the manuscript. K.Z. and K.R. provided insightful discussions, reviewed the results and revised the manuscript. All authors have read and approved the final manuscript.

\section{Funding}

Not applicable.

\section{Availability of data and materials}

The datasets used during the current study are available from the corresponding author on reasonable. request.

\section{Ethics approval and consent to participate}

The need for informed consent for this study, which used existing patient records, was waived by the Institutional Review Board (IRB) of Washington University in Saint Louis (IRB ID \# 201801090).

\section{Consent for publication}

Not applicable.

\section{Competing interests}

There are no competing interests for A.G., K.Z., and K.R. The corresponding author (R.F.) is an editorial board member for the journal.

\section{Author details}

${ }^{1}$ Institute for Informatics (I2), Washington University School of Medicine, 600 S. Taylor Avenue, Suite 102, Campus Box 8102, St. Louis, MO 63110, USA. ${ }^{2}$ Cardiovascular Division, Department of Internal Medicine, Washington University School of Medicine, St. Louis, MO, USA. ${ }^{3}$ Department of Research and Evaluation Southern California Permanente Medical Group, Pasadena, California, USA. ${ }^{4}$ Department of Health Systems Science, Kaiser Permanente School of Medicine, Pasadena, California, USA. ${ }^{5}$ Division of General Medical Sciences, Department of Internal Medicine, Washington University School of Medicine, 600 S. Taylor Avenue, Suite 102, Campus Box 8102, St. Louis, MO 63110, USA.

Received: 4 January 2020 Accepted: 5 May 2020

Published online: 13 May 2020

\section{References}

1. Amsterdam E. Primary prevention of coronary heart disease in men and women: does 1 size fit all? Yes! Clin Cardiol. 2011;34(11):658-62.
2. Byers T, Patnaik JL. Missed opportunities for chronic disease prevention after breast cancer. Women Health. 2011;7(6):619-21. https://doi.org/10.2217/ whe.11.66.

3. Patnaik JL, Byers T, DiGuiseppi C, Dabelea D, Denberg TD. Cardiovascular disease competes with breast cancer as the leading cause of death for older females diagnosed with breast cancer: a retrospective cohort study. Breast Cancer Res. 2011;13(3):R64

4. Park N-J, Chang Y, Bender C, et al. Cardiovascular disease and mortality after breast cancer in postmenopausal women: results from the Women's health initiative. PLoS One. 2017;12(9):e0184174. https://doi.org/10.1371/journal. pone.0184174.

5. Miller KD, Siegel RL, Lin CC, et al. Cancer treatment and survivorship statistics, 2016. CA Cancer J Clin. 2016. https://doi.org/10.3322/caac.21349.

6. U.S. Breast Cancer Statistics. Https://Www.Breastcancer.Org/Symptoms/ Understand bc/Statistics. 2020. Accessed 13 Jan 2020.

7. Mehta LS, Watson KE, Barac A, et al. Cardiovascular disease and breast Cancer: where these entities intersect: a scientific statement from the American Heart Association. Circulation. 2018;137(8):e30-66. https://doi.org/ 10.1161/cir.0000000000000556.

8. Abdel-Qadir H, Austin PC, Lee DS, et al. A population-based study of cardiovascular mortality following early-stage breast cancer. JAMA Cardiol. 2017. https://doi.org/10.1001/jamacardio.2016.3841.

9. Hawkes AL, Lynch BM, Owen N, Aitken J. Lifestyle factors associated concurrently and prospectively with co-morbid cardiovascular disease in a population-based cohort of colorectal cancer survivors. Eur J Cancer. 2011; 47(2):267-76

10. Koene RJ, Prizment AE, Blaes A, Konety SH. Shared risk factors in cardiovascular disease and cancer. Circulation. 2016. https://doi.org/10.1161/ CIRCULATIONAHA.115.020406.

11. Meijers WC, De Boer RA. Common risk factors for heart failure and cancer. Cardiovasc Res. 2019. https://doi.org/10.1093/cvr/cvz035.

12. AHA. Life's Simple 7. Association AH, 2013. http://mylifecheck.heart.org/.

13. Polonsky TS, Ning H, Daviglus ML, et al. Association of Cardiovascular Health With Subclinical Disease and Incident Events: The Multi-Ethnic Study of Atherosclerosis. J Am Heart Assoc. 2017;6(3). https://doi.org/10.1161/JAHA 116.004894.

14. Bambs C, Kip KE, Dinga A, Mulukutla SR, Aiyer AN, Reis SE. Low prevalence of "ideal cardiovascular health" in a community-based population / clinical perspective. Circulation. 2011;123(8):850-7. https://doi.org/10.1161/ circulationaha.110.980151.

15. Folsom AR, Yatsuya H, Nettleton JA, Lutsey PL, Cushman M, Rosamond WD. Community prevalence of ideal cardiovascular health, by the American Heart Association definition, and relationship with cardiovascular disease incidence. J Am Coll Cardiol. 2011;57(16):1690-6. https://doi.org/10.1016/j. jacc.2010.11.041.

16. Shay CM, Ning H, Allen NB, et al. Status of cardiovascular health in US adults: prevalence estimates from the National Health and nutrition examination surveys (NHANES) 2003-2008. Circulation. 2011. https://doi.org/ 10.1161/circulationaha.111.035733.

17. Erqou S, Ajala O, Bambs CE, et al. Ideal cardiovascular health metrics in couples: a community-based study. J Am Heart Assoc. 2018. https://doi.org/ 10.1161/JAHA.118.008768.

18. Ghimire U, Shrestha N, Gyawali B, Pradhan PMS, Mishra SR. Prevalence of American Heart Association defined ideal cardiovascular health metrics in Nepal: findings from a nationally representative cross-sectional study. Int Health. 2019. https://doi.org/10.1093/inthealth/ihz088.

19. Benziger CP, Zavala-Loayza JA, Bernabe-Ortiz A, et al. Low prevalence of ideal cardiovascular health in Peru. Heart. 2018. https://doi.org/10.1136/ heartjnl-2017-312255.

20. Foraker RE, Abdel-Rasoul M, Kuller LH, et al. Cardiovascular health and incident cardiovascular disease and cancer: the Women's health initiative. Am J Prev Med. 2016;50(2):236-40.

21. Weaver $\mathrm{K}$, Foraker $\mathrm{R}$, Alfano $\mathrm{C}$, et al. Cardiovascular risk factors among longterm survivors of breast, prostate, colorectal, and gynecologic cancers: a gap in survivorship care? J Cancer Surviv. 2013;7(2):253-61. https://doi.org/ 10.1007/s11764-013-0267-9.

22. Kapoor A, Prakash V, Sekhar M, et al. Monitoring risk factors of cardiovascular disease in cancer survivors. Clin Med J R Coll Physicians London. 2017. https://doi.org/10.7861/clinmedicine.17-4-293.

23. Thomson C, Rock C, Thompson $\mathrm{P}$, et al. Vegetable intake is associated with reduced breast cancer recurrence in tamoxifen users: a secondary analysis 
from the Women's healthy eating and living study. Breast Cancer Res Treat. 2011;125(2):519-27. https://doi.org/10.1007/s10549-010-1014-9.

24. Jones LW, Haykowsky MJ, Swartz JJ, Douglas PS, Mackey JR. Early breast Cancer therapy and cardiovascular injury. J Am Coll Cardiol. 2007;50(15): 1435-41. https://doi.org/10.1016/j.jacc.2007.06.037.

25. Darby SC, McGale P, Taylor CW, Peto R. Long-term mortality from heart disease and lung cancer after radiotherapy for early breast cancer: prospective cohort study of about 300000 women in US SEER cancer registries. Lancet Oncol. 2005;6(8):557-65. https://doi.org/10.1016/S14702045(05)70251-5.

26. Mark L, Zablotska L, E lipshultz S. Ischemic Heart Disease after Breast Cancer Radiotherapy. N Engl J Med. 2013;368:2523-7.

27. Darby SC, Ewertz M, et al. Risk of ischemic heart disease in women after radiotherapy for breast Cancer. N Engl J Med. 2013;368:987-98.

28. Yu AF, Jones LW. Breast cancer treatment-associated cardiovascular toxicity and effects of exercise countermeasures. Cardio-Oncology. 2016. https://doi. org/10.1186/s40959-016-0011-5

29. Han X, Zhou Y, Liu W. Precision cardio-oncology: understanding the cardiotoxicity of cancer therapy. npj Precis Oncol. 2017. https://doi.org/10. 1038/s41698-017-0034-X.

30. Zagar TM, Cardinale DM, Marks LB. Breast cancer therapy-associated cardiovascular disease. Nat Rev Clin Oncol. 2016. https://doi.org/10.1038/ nrclinonc.2015.171.

31. Gulati M, Mulvagh SL. The connection between the breast and heart in a woman: breast cancer and cardiovascular disease. Clin Cardiol. 2018. https:// doi.org/10.1002/clc.22886.

32. Gernaat SAM, Ho PJ, Rijnberg N, et al. Risk of death from cardiovascular disease following breast cancer: a systematic review. Breast Cancer Res Treat. 2017. https://doi.org/10.1007/s10549-017-4282-9.

33. Boekel NB, Schaapveld M, Gietema JA, et al. Cardiovascular disease risk in a large, population-based cohort of breast Cancer survivors. Int J Radiat Oncol Biol Phys. 2016. https://doi.org/10.1016/j.jpobp.2015.11.040.

34. IOM. Cancer Survivorship Care Planning. 2005. http://www.iom.edu/ / media/Files/Report Files/2005/From-Cancer-Patient-to-Cancer-Survivor-Lostin-Transition/factsheetcareplanning.pdf.

35. Enright K, Krzyzanowska M. Control of cardiovascular risk factors among adult cancer survivors: a population-based survey. Cancer Causes Control. 2010;21(11):1867-74. https://doi.org/10.1007/s10552-010-9614-6.

36. O'Regan R, Giblin J. Cancer survivorship: a local and global issue. Lancet. 2013;382(9891):497-8.

37. Tanz R, Magne N, Annede P, et al. Towards an integrated approach to cardiovascular toxicities related to the treatments of breast cancer. Bull Cancer. 2014;101(7-8):730-40.

38. Lloyd-Jones DM, Hong Y, Labarthe D, et al. Defining and setting National Goals for cardiovascular health promotion and disease reduction. Circulation. 2010;121(4):586-613. https://doi.org/10.1161/circulationaha.109. 192703

39. Cortes C, Vapnik V. Support-vector networks. Mach Learn. 1995. https://doi. org/10.1023/A:1022627411411.

40. Safavian SR, Landgrebe D. A survey of decision tree classifier methodology. IEEE Trans Syst Man Cybern. 1991. https://doi.org/10.1109/21.97458.

41. Hosmer D, Lemeshow S, Sturdivant RX. Model-building strategies and methods for logistic regression. In: Applied Logistic Regression; 2013. https://doi.org/10.1002/0471722146.ch4.

\section{Publisher's Note}

Springer Nature remains neutral with regard to jurisdictional claims in published maps and institutional affiliations.

Ready to submit your research? Choose BMC and benefit from:

- fast, convenient online submission

- thorough peer review by experienced researchers in your field

- rapid publication on acceptance

- support for research data, including large and complex data types

- gold Open Access which fosters wider collaboration and increased citations

- maximum visibility for your research: over $100 \mathrm{M}$ website views per year

At BMC, research is always in progress.

Learn more biomedcentral.com/submissions 